\title{
Biomarkers of Selenium Toxicity after Sub-Acute Exposure in Mice
}

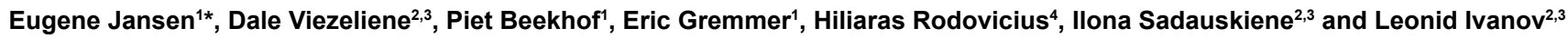

${ }^{1}$ Centre for Health Protection, National Institute for Public Health and the Environment, The Netherlands

${ }^{2}$ Department of Biochemistry, Medical Academy, Lithuanian University of Health Sciences, Kaunas, Lithuania

${ }^{3}$ Neuroscience Institute, Medical Academy, Lithuanian University of Health Sciences, Kaunas, Lithuania

${ }^{4}$ Department of Drug Chemistry, Medical Academy, Lithuanian University of Health Sciences, Kaunas, Lithuania

\begin{abstract}
Selenium (Se) is a trace element, essential for human health but it can be toxic at moderately higher intake levels. In this study biomarkers of Se toxicity after sub-acute intra-peritoneal exposure to Se $(62.5 \mu \mathrm{g} \mathrm{Se} / \mathrm{kg} \mathrm{bw} /$ day; 14 days) were investigated in mice. Such exposure corresponds to high human Se-intake levels. Focus was put on the biomarkers of systemic effects and on the toxicity in liver, kidney and brain. The sub-acute exposure to Se resulted in an increase in the concentrations of systemic inflammation biomarkers IL-6 $(p=0.025)$ and resistin $(p=0.049)$ and in a decrease of TNF- $\alpha(p=0.008)$. No effect on concentrations of MCP-1, tPAI-1, leptin and insulin was observed in serum. Also biomarkers of oxidative stress, anti-oxidant parameters and enzymes ALT and AST were not affected.
\end{abstract}

In the tissue homogenates of liver, kidney and brain changes were observed in the activities of enzymes LDH $(p=0.013)$, ALP $(p=0.0009)$ and GGT $(p=0.0047)$. In the brain homogenate an influx of TG $(p=0.0044)$ and a decrease in the total GSH concentration $(p=0.008)$ was observed.

It was concluded that although the sub-acute exposure to a relatively high concentration of Se causes an increase in concentration of some biomarkers of intracellular processes, especially in the brain, the effect of Se can be considered as low toxicity.

Keywords: Selenium; Biomarkers; Toxicity; Oxidative stress; Inflammation; Redox status

Abbreviations: ALP: Alkaline Phosphatase; ALT: Alanine Aminotransferase; AST: Aspartate Aminotransferase; FRAP: Ferric Reducing Ability of Plasma; GGT: $\gamma$-Glutamyl Transferase; GSH: Glutathione; IL-6: Interleukin-6; LDH: Lactate Dehydrogenase; MCP-1: Monocyte Chemotactic Protein-1; ROM: Reactive Oxygen Metabolites; Se: Selenium; TG: Total Triglycerides; TNF- $\alpha$ : Tumor Necrosis Factor Alpha; tPAI-1: tissue Plasminogen Activator Inhibitor-1.

\section{Introduction}

Selenium (Se) is a naturally occurring trace element, which is essential to human and animal health but can be harmful in excess intake.

On one hand, a low selenium status has been associated with increased risk of some diseases, poor immune function, and cognitive decline [1]. An optimal selenium status has a beneficial effect on male and female reproduction [2], autoimmune thyroid disease [3] and decreases risk on prostate, lung, colorectal, and bladder cancer $[4,5]$.

On the other hand, Se poisoning due to environmental exposure and improper supplementation has been demonstrated in humans and livestock [6]. Yang et al. [7] described an endemic human disease in China, due to high environmental concentration of Se which was characterized by the loss of hair and nails, skin lesions, and nervous system disorders. Selenium supplementation of people who already have an adequate intake might increase their risk of Type-2 diabetes [8].

Compared with other trace elements, selenium has one of the narrowest ranges between the dietary deficiency ( $40 \mu \mathrm{g} /$ day $)$ and toxic levels (400 $\mu \mathrm{g} /$ day) [9], which makes it necessary to carefully control Se intake by humans and animals. The major factor that needs to be emphasized with regard to the health effects of selenium is its U-shaped effect $[1,10]$. Additional selenium intake may benefit people with low status, whereas those with adequate-to-high status might be affected adversely and should not take selenium supplements [11].

For a deeper insight into the possible toxicity of Se, the present study investigated biomarkers of possible adverse effects of sub-acute exposure to Se. Both the biomarkers of systemic and intracellular inflammation and the redox status of mouse liver, kidney, and brain were investigated.

\section{Materials and Methods}

\section{Experimental animals and exposure protocol}

Balb/c mice weighing 20-25 g were exposed to Sodium Selenite $\left(\mathrm{Na}_{2} \mathrm{SeO}_{3}\right.$, from Sigma-Aldrich, Munich, Germany) by a daily intra peritoneal injection of $0.20-0.25 \mathrm{~mL}$ of a solution (100:1/body weight: volume) of $62.5 \mu \mathrm{g} \mathrm{Se} / \mathrm{kg}$ body weight (bw) for 14 days. This dose corresponds to $0.025 \mathrm{LD} 50$ ( LD50 $=2500 \mu \mathrm{g} / \mathrm{kg}$ ) which was established in this laboratory earlier.

The control group received a daily intra peritoneal injection of the same volume of a saline solution (100:1/ body weight: volume). Each group consisted of eight male animals. Next day after the last injection,

${ }^{*}$ Corresponding author: Eugene Jansen, Centre for Health Protection, National Institute for Public Health and the Environment, Bilthoven, The Netherlands, Tel: +31-302742940; E-mail: eugene.jansen@rivm.nl

Received September 30, 2013; Accepted October 30, 2013; Published November 04, 2013

Citation: Jansen E, Viezeliene D, Beekhof P, Gremmer E, Rodovicius H, et al. (2013) Biomarkers of Selenium Toxicity after Sub-Acute Exposure in Mice. J Mol Biomark Diagn 4: 150. doi:10.4172/2155-9929.1000150

Copyright: ( 2013 Jansen E, et al. This is an open-access article distributed under the terms of the Creative Commons Attribution License, which permits unrestricted use, distribution, and reproduction in any medium, provided the original author and source are credited 
the mice were anaesthetized and terminated. The organs (liver, kidney and brain) were rapidly removed and cooled on ice.

All procedures were performed according to the Republic of Lithuania Law on the Care, Keeping and Use of Animals (License of State Veterinary Service for working with laboratory animals No 0200).

Preparation of tissue samples: The liver, kidney and brain were homogenized in 3 volumes (weight/volume) of homogenization buffer (50 mmol/L Tris-HCl, pH 7.6; 5 mmol/L MgCl; $60 \mathrm{mmol} / \mathrm{L} \mathrm{KCl;} 25$ $\mathrm{mmol} / \mathrm{L}$ sucrose). The tissue homogenates were centrifuged at 3000 rpm for $10 \mathrm{~min}(1,000 \mathrm{~g})$ in a Beckman J2-21 centrifuge. The pellet was discarded and $100 \mu \mathrm{L}$ of the first supernatant was immediately frozen at $-80^{\circ} \mathrm{C}$. The remaining volume of the first supernatant was centrifuged at $10000 \mathrm{rpm}$ for $15 \mathrm{~min}(12,000 \mathrm{~g})$ in a Beckman J2-21 centrifuge. The second supernatant (post-mitochondrial supernatant) was immediately frozen at $-80^{\circ} \mathrm{C}$.

All the samples were shipped on dry ice from the Lithuanian University of Health Sciences in Kaunas, Lithuania to the National Institute of Public Health and the Environment in Bilthoven, The Netherlands. The samples were received frozen and stored at $-80^{\circ} \mathrm{C}$ until analysis.

Preparation of blood samples: Whole blood was collected after mouse decapitation into Eppendorf test tubes. Blood was centrifuged at $4000 \mathrm{rpm}$ for $10 \mathrm{~min}(1,600 \mathrm{~g})$. Serum samples were immediately frozen

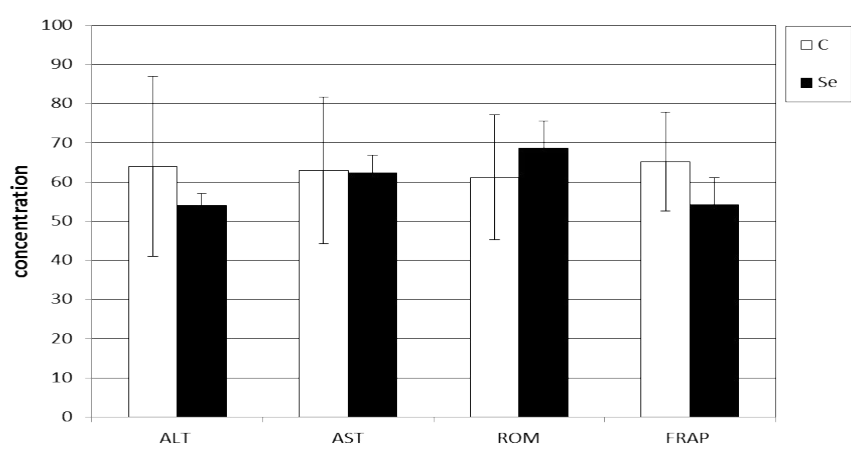

Figure 1: Serum enzyme activities of ALT and AST (both expressed in U/ $\mathrm{mL}$ ) and concentrations of ROM (expressed in U/L) and FRAP (expressed in $\mu \mathrm{mol} / \mathrm{L}$ ) after treatment with Se. The values for AST and FRAP were multiplied by a factor of 0.2 and 0.05 respectively to fit in the figure.

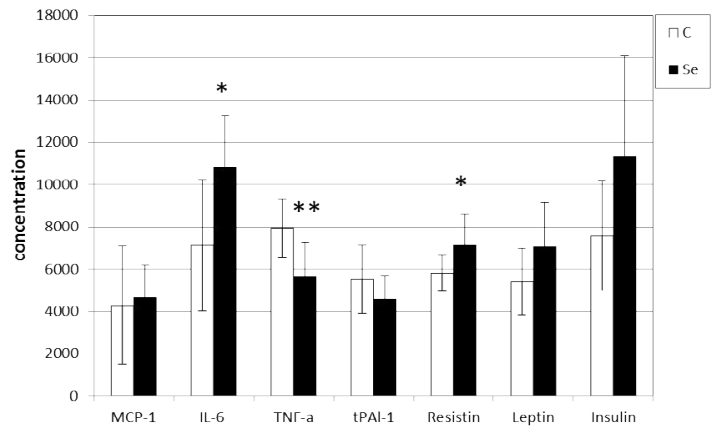

Figure 2: Serum concentrations of the biomarkers MCP-1 (expressed in $\mathrm{pg} / \mathrm{mL}$ ), IL-6, TNF-a (both expressed in pg/L), tPAl-1, Resistin, Leptin and Insulin (all expressed in $\mathrm{pg} / \mathrm{mL}$ ), after treatment with Se. The values for MCP-1, Resistin, Leptin and Insulin were multiplied by a factor of 100, 5, 2 and 5 , respectively to fit in the figure. Statistics: * $p<0.05$ vs. control group; ${ }^{* *} p<0.01$ vs. control group. at $-80^{\circ} \mathrm{C}$. All samples were shipped from Kaunas to Bilthoven on dry ice. The samples were received frozen and stored at $-80^{\circ} \mathrm{C}$ until analysis.

Biomarker analysis: Biomarkers of oxidative stress and antioxidant status, Reactive Oxygen Metabolites (ROM) and Ferric Reducing Ability of Plasma (FRAP), were determined in an Autoanalyser (LX-20 Pro, Beckman Coulter, Mijdrecht, the Netherlands). ROM was determined using the kit from Diacron, Grosseto, Italy. The FRAP antioxidant assay was measured according to Benzie and Strain [12]. The relative activities of samples were assessed by comparing their activities with that of Trolox. These two assays were adapted to the LX20 analyzer. Intra assay coefficients of variation were $2.1 \%$ for ROM and $3.4 \%$ for FRAP.

As biomarkers of tissue toxicity, the enzyme activities of Alanine Aminotransferase (ALT) and Aspartate Aminotransferase (AST) were determined in serum. ALT, AST, Alkaline Phosphatase (ALP), $\gamma$-Glutamyltransferase (GGT), Lactate Dehydrogenase (LDH) and Total Triglycerides (TG) were determined in tissue homogenates on the same Auto-Analyzer using dedicated kits from Beckman-Coulter, Woerden, the Netherlands.

The Inflammation Biomarkers, Interleukin-6 (IL-6), Tumor Necrosis Factor Alpha (TNF- $\alpha$ ), tissue Plasminogen Activator Inhibitor-1 (tPAI-1), Monocyte Chemotactic Protein-1 (MCP-1), Resistin, Leptin and Insulin, were determined with a Mouse Adipokine kit (Millipore, Amsterdam, The Netherlands) using the Luminex technique. Intra assay coefficients of variation were $6.4 \%$ for IL-6, $4.9 \%$ for TNF- $\alpha, 7.4 \%$ for PAI- $1,10.0 \%$ for MCP-1, 5.2\% for Resistin, 5.6\% for Leptin and 9.3\% for Insulin.

Total glutathione (totGSH) in the liver homogenate was measured after deproteinization followed by incubation with glutathione reductase to transform oxidized to reduced glutathione. Then the totGSH was determined after derivatization with 5,5'-dithiobis-(2-nitrobenzoic acid). The reaction product was measured using an auto-analyzer (LX20 Pro, Beckman Coulter, Woerden, the Netherlands). The intra assay variation was $6.7 \%$.

All concentrations from the tissue homogenates were adjusted for the protein content of the samples.

Statistical analysis: The data were analyzed by means of Student's $t$ test. Results were expressed as the mean \pm standard error of mean. Statistical significance was set at $\mathrm{p}<0.05$.

\section{Results}

\section{Biomarkers of systemic toxicity}

The effect of exposure to a relatively high dose of Se on the circulation was studied by measuring a number of serum biomarkers. Because of the limited amount of mouse serum that was available, a choice was made for the following biomarkers. MCP-1, IL-6, TNF- $\alpha$, tPAI-1, Resistin, Leptin and Insulin were selected as biomarkers for inflammation. Biomarkers of oxidative stress were assessed by measuring hydroperoxides (ROM), the total antioxidant status by FRAP and liver toxicity by the enzymes ALT and AST.

Figure 1 shows effects of Se on the activity of ALT and AST and on the concentration of oxidative stress parameters ROM and FRAP. Exposure to Se did not have any statistically significant effect on these parameters. The decrease in FRAP concentration was almost statistically significant with a p-value of 0.078 .

The effect of administration of Se on the inflammatory biomarkers 


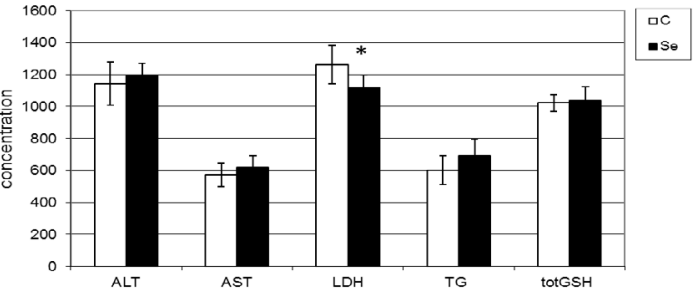

Figure 3: The effects of sub-acute exposure to Se on enzyme activities of ALT, AST, LDH (all expressed in U/g protein) and concentrations of TG and totGSH (both expressed in $\mu \mathrm{mol} / \mathrm{g}$ protein) in the liver postmitochondrial supernatants. The values for LDH, TG and totGSH were multiplied by a factor of $0.2,10$ and 5 , respectively to fit in the figure. Statistics: ${ }^{*} p<0.05$ vs. control group.

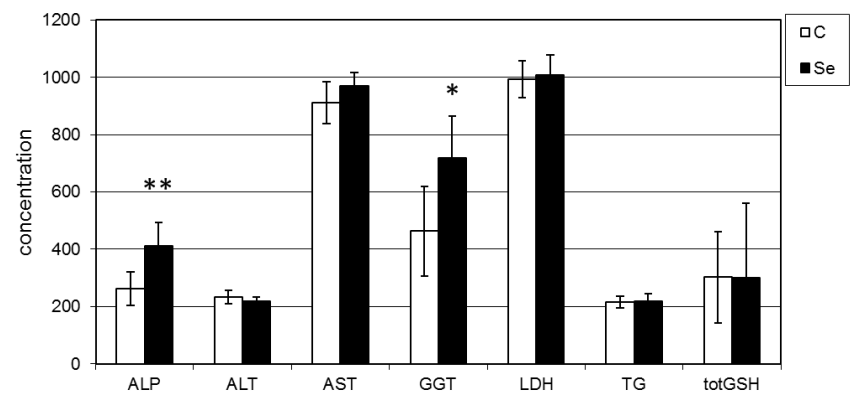

Figure 4: The effects of sub-acute exposure to Se on enzyme activities of ALP, ALT, AST, GGT and LDH (all expressed in $\mathrm{U} / \mathrm{g}$ protein) and concentrations of TG and totGSH (both expressed in $\mu \mathrm{mol} / \mathrm{g}$ protein) in kidney post-mitochondrial supernatants. The values for ALT, LDH and totGSH were multiplied by a factor of $2.0,0.125$ and 5 , respectively to fit in the figure. Statistics: ${ }^{*} p<0.005$ vs. control group; ${ }^{* *} p<0.001$ vs. control group.

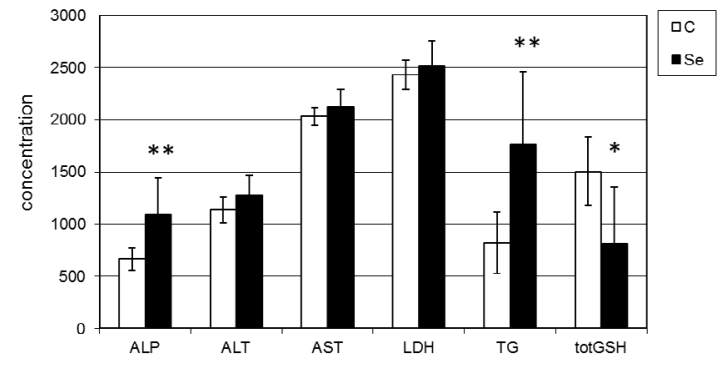

Figure 5: The effects of sub-acute exposure to Se on enzyme activities of ALP, ALT, AST and LDH (all expressed in U/g protein) and concentrations of TG and totGSH (both expressed in $\mu \mathrm{mol} / \mathrm{g}$ protein) in brain postmitochondrial supernatants. The values for TG and totGSH were multiplied by a factor of 100 to fit in the figure. Statistics: * $p<0.01$ vs. control group; ${ }^{* *} p<0.005$ vs. control group.

is demonstrated in Figure 2. Treatment with Se resulted in substantial higher mean values of IL-6 (from 7141 to $10791 \mathrm{pg} / \mathrm{L}$ ), Resistin (from 1164 to $1424 \mathrm{pg} / \mathrm{mL}$ ) and Insulin (from 1518 to $2265 \mathrm{pg} / \mathrm{mL}$ ) and in lower mean values of TNF- $\alpha$ (from 7930 to $5630 \mathrm{pg} / \mathrm{L}$ ) and tPAI-1 (from 5523 to $4599 \mathrm{pg} / \mathrm{mL}$ ). The increases in the concentration of the inflammation biomarkers IL- 6 and Resistin were statistically significant. The p-values for IL-6, Resistin and TNF- $\alpha$ were $0.025,0.049$ and 0.008 , respectively. The increase of insulin concentration was not statistically significant $(\mathrm{p}=0.088)$.

\section{Biomarkers of hepatic toxicity}

In the post-mitochondrial supernatant of the liver the following biomarkers of toxicity were measured: ALP, ALT, AST, GGT, LDH, TG and totGSH, as a biomarker of the redox status. The levels of the enzymes ALP and GGT were below the limit of detection. After exposure to Se, the activity of LDH showed a small but statistically significant lower mean value ( $6315 \mathrm{U} / \mathrm{g}$ protein) compared with that of the control group (5610 U/g protein) with a p-value of 0.013 (Figure 3 ). Activities of ALT, AST and concentrations of TG and totGSH did not change upon exposure to Se.

\section{Biomarkers of renal toxicity}

In the post-mitochondrial supernatant of the kidney the following biomarkers were measured: ALP, ALT, AST, GGT, LDH, TG and totGSH After exposure to Se, the activities of ALP and GGT were statistically significantly higher than those of the control group as shown in Figure 4. The activity of ALP increased from 263 to $412 \mathrm{U} / \mathrm{g}$ protein $(\mathrm{p}=0.0009)$ and the activity of GGT from 464 to $718 \mathrm{U} / \mathrm{g}$ protein $\mathrm{p}=0.0047$ ). The activities of ALT, AST and LDH did not change upon exposure to Se. The totGSH and TG concentrations did not change either.

\section{Biomarkers of brain toxicity}

In the post-mitochondrial supernatant of the brain the following biomarkers were measured: ALP, ALT, AST, LDH, TG and totGSH. The activity of GGT was below the limit of detection. On exposure to Se, the ALP activity was statistically significantly higher (1098 U/g protein) compared with that of the control group (664 U/g protein) with a $p$ value of 0.0043 as shown in Figure 5. The activities of ALT, AST and LDH did not change significantly. The total TG concentration was statistically significantly higher in the Se-treated group (0.82 vs. 1.77 $\mu \mathrm{mol} / \mathrm{g}$ protein) with a $\mathrm{p}$-value of 0.0044 . The biomarker of the redox status (totGSH) in the brain was unexpectedly lower after exposure to Se $(1.50 \mathrm{vs.} 0.81 \mu \mathrm{mol} / \mathrm{g}$ protein) with a p-value of 0.008 .

\section{Discussion}

Toxic effects of Se were investigated in mice by measuring a number of biomarkers after sub-acute exposure for 14 days at a high dose level of Se which can also be found in human exposure studies $[13,14]$.

A daily dose of $62.5 \mu \mathrm{g} \mathrm{Se} / \mathrm{kg}$ bw for 14 days did not affect the systemic oxidative stress and antioxidant status as measured by ROM and FRAP, respectively. ROM is an established biomarker of oxidative stress and is linked to several diseases $[15,16]$. The liver toxicity was determined by the increase in the activity of liver enzymes ALT and AST, however, the activities of these enzymes in serum did not change. Possible effects of systemic inflammation parameters were studied by the measurement of the most common biomarkers IL-6, TNF- $\alpha$, tPAI1, MCP-1, Resistin, Leptin and Insulin. With the presently used dose of Se not many changes were observed either. The systemic concentrations of MCP-1, tPAI-1 and Leptin were not affected. The concentration of insulin was increased, but due to the large variation the increase did not reach statistical significance. It was reported that Se has insulinmimetic properties, probably by the stimulation of tyrosine kinases involved in the insulin signaling cascade [3].

A statistically significant increase of IL- 6 and Resistin concentrations was observed, whereas TNF- $\alpha$ concentration decreased. Usually both IL- 6 and TNF- $\alpha$ are induced in a similar manner, but unexpectedly, this was not the case in this study. Probably Resistin activates transcriptional events, leading to an increased expression of IL- 6 and not of TNF- $\alpha$ [3]. Our data are however consistent with those reported in a previous study 
on the acute toxic effects of aluminium and Se in which also an increase in IL-6 concentration was found, whereas no significant changes were observed for TNF- $\alpha$ and tPAI-1 [3]. One of the functions of IL-6 is an anti-inflammatory action stimulating regeneration and repair through the STAT 3 pathway [17]. It has been suggested that by this pathway IL-6 is involved in the repair process responding to oxidative stress and depletion of reduced glutathione $[18,19]$. This observation is in agreement with the intracellular decrease in GSH in the brain observed in this study.

Besides systemic toxicity, the possible toxic effects in liver, kidney and brain tissue were studied. For the assessment of organ specific toxicity the activities of several enzymes and the TG concentration were measured in the post-mitochondrial tissue extracts. In the liver only LDH showed a small but statistically significant decrease of activity, whereas the activities of other enzymes, ALT and AST, did not change. In the kidney and brain a statistically significant increase in the activity of ALP was observed, and the activity of GGT increased in the kidney. Also in a human study, a not statistically significant increase in the activity of ALP was observed after intake of a high dose of Se of 3200 $\mu \mathrm{g} /$ day [20]. In a recent human study of Alzheimer patients, a $13 \%$ increase in the brain ALP activity was observed, which was inversely correlated with cognitive function [21]. In order to monitor possible disturbances of the lipid pathways TG concentration was measured in all tissues. However, an influx of lipids was observed only in the brain but not in other tissues.

For technical reasons it was not possible to perform the ROM assay routinely in the tissue extracts without major changes in the assay performance. Therefore the totGSH concentration was measured as a biomarker of the redox status [22]. The concentration of totGSH in the liver and kidney did not change, but in the brain tissue a statistically significant decrease was observed.

There are some incident case reports in which the toxicity of selenite or selenocysteine was investigated in mice. But in all studies there were very high doses of Se in the $\mathrm{mg} / \mathrm{kg}$ bw range used. The increased activities of AST and ALT were observed after 60 and 90 days of mice exposure to 10-15 mg selenocystine/kg bw/day [23]. Johnson et al. [24] found an increased level of mRNA of TNF- $\alpha$ and IL- $1 b$ in macrophages after exposure to selenite in drinking water at the highest dose of $9 \mathrm{ppm}$. Sun et al. [25] found increased levels of Superoxid Dismutase (SOD) and Glutathione Transferase (GST) after 5-day i.p. injections of $3 \mathrm{mg} /$ $\mathrm{kg}$ bw selenite in mice. Sayato et al. [26] used different concentrations of selenocysteine in mice. They found an increase in the activities of ALT and AST one day after exposure to $50 \mathrm{mg} / \mathrm{kg}$ bw. After 2-10 days their levels returned to normal values. Zhang et al. [27] exposed mice to Se for 14 days with an i.p. injection of $2 \mathrm{mg}$ selenite $/ \mathrm{kg}$ bw and found a significant increase in the activities of ALT and AST, a decrease in the liver glutathione peroxidase and SOD, and an increase in GST and Thioredoxin Reductase. All these effects were observed at even higher dose levels than those used in the present study. In this study the moderately high dose of Se in brain will probably increase levels of glutathione peroxidase and glutathione transferase, which can cause a temporarily substrate depletion of the GSH levels [25].

In this mice study a daily dose of $62.5 \mu \mathrm{g} \mathrm{Se} / \mathrm{kg}$ bw (0.025 LD50) was used, which corresponds to $4375 \mu \mathrm{g} \mathrm{Se/day} \mathrm{in} \mathrm{human} \mathrm{high} \mathrm{intake}$ studies. This level of intake was also found in human populations. In an Inuit population intakes of Se were reported up to $5885 \mu \mathrm{g} \mathrm{Se} /$ day (probably organic Se), without any signs of selenosis [13]. In another study [14] the lowest-observed-adverse-effect-level based on hair loss and nail changes was established at $2000 \mu \mathrm{g}$ Se per day, whereas toxicity occurs at a dose of $6300 \mu \mathrm{g}$ Se per day.

To establish a more precise no-observed-adverse-effect-level for the effects in this study, a dose-response approach would be appropriate. In addition, the route of exposure should be investigated in more detail, i.p. versus oral exposure [28-30].

The present study indicates that toxic effects of higher doses of Se were observed in both systemic and tissue-specific biomarkers, but these effects are possibly reversible and of low toxicity level. However, the effects observed in brain tissue should not be ignored or overlooked. Moreover, in this study mice were exposed for only 2 weeks and it cannot be excluded that exposure for a longer period might lead to more severe adverse effects.

\section{References}

1. Rayman MP (2012) Selenium and human health. Lancet 379: 1256-1268.

2. Mistry HD, Broughton Pipkin F, Redman CW, Poston L (2012) Selenium in reproductive health. Am J Obstet Gynecol 206: 21-30.

3. Beckett GJ, Arthur JR (2005) Selenium and endocrine systems. J Endocrinol 184: 455-465.

4. Rayman MP (2005) Selenium in cancer prevention: a review of the evidence and mechanism of action. Proc Nutr Soc 64: 527-542.

5. Hurst R, Hooper L, Norat T, Lau R, Aune D, et al. (2012) Selenium and prostate cancer: systematic review and meta-analysis. Am J Clin Nutr 96: 111-122.

6. Fordyce FM (2013) Selenium Deficiency and Toxicity in the Environment Essentials of Medical Geology 375-416.

7. Yang GQ, Wang SZ, Zhou RH, Sun SZ (1983) Endemic selenium intoxication of humans in China. Am J Clin Nutr 37: 872-881.

8. Stranges S, Sieri S, Vinceti M, Grioni S, Guallar E, et al. (2010) A prospective study of dietary selenium intake and risk of type 2 diabetes. BMC Public Health 10: 564

9. World Health Organization, Food and Agriculture Organization, Internationa Atomic Energy Agency Expert Group (1996). Trace Elements in Human Nutrition and Health. Geneva: WHO.

10. http://www.nap.edu/catalog.php?record_id=9810

11. http://ods.od.nih.gov/factsheets/Selenium-HealthProfessional /

12. Benzie IF, Strain JJ (1996) The ferric reducing ability of plasma (FRAP) as measure of "antioxidant power": the FRAP assay. Anal Biochem 239: 70-76.

13. Hansen JC, Pedersen HS (1986) Environmental exposure to heavy metals in North Greenland. Arctic Med Res 41: 21-34.

14. Whanger $P$, Vendeland S, Park YC, Xia Y (1996) Metabolism of subtoxic levels of selenium in animals and humans. Ann Clin Lab Sci 26: 99-113.

15. Leufkens AM, van Duijnhoven FJ, Woudt SH, Siersema PD, Jenab M, et al (2012) Biomarkers of oxidative stress and risk of developing colorectal cancer: a cohort-nested case-control study in the European Prospective Investigation Into Cancer and Nutrition. Am J Epidemiol 175: 653-663.

16. Vassalle C, Bianchi S, Battaglia D, Landi P, Bianchi F, et al. (2012) Elevated levels of oxidative stress as a prognostic predictor of major adverse cardiovascular events in patients with coronary artery disease. J Atheroscler Thromb 19: 712-717.

17. Nagaev I, Bokarewa M, Tarkowski A, Smith U (2006) Human resistin is a systemic immune-derived proinflammatory cytokine targeting both leukocytes and adipocytes. PLoS One 1: e31.

18. Viezeliene D, Beekhof P, Gremmer E, Rodovicius H, Sadauskiene I, et al (2013) Selective induction of IL-6 by aluminum-induced oxidative stress can be prevented by selenium. J Trace Elem Med Biol 27: 226-229.

19. Taub R (2003) Hepatoprotection via the IL-6/Stat3 pathway. J Clin Invest 112 978-980.

20. Galun E, Zeira E, Pappo O, Peters M, Rose-John S (2000) Liver regeneration induced by a designer human IL-6/sIL-6R fusion protein reverses severe hepatocellular injury. FASEB J 14: 1979-1987. 
Citation: Jansen E, Viezeliene D, Beekhof P, Gremmer E, Rodovicius H, et al. (2013) Biomarkers of Selenium Toxicity after Sub-Acute Exposure in Mice. J Mol Biomark Diagn 4: 150. doi:10.4172/2155-9929.1000150

21. Haga S, Terui K, Zhang HQ, Enosawa S, Ogawa W, et al. (2003) Stat3 protects against Fas-induced liver injury by redox-dependent and -independent mechanisms. J Clin Invest 112: 989-998.

22. Reid ME, Stratton MS, Lillico AJ, Fakih M, Natarajan R, et al. (2004) A report of high-dose selenium supplementation: response and toxicities. J Trace Elem Med Biol 18: 69-74

23. Vardy ER, Kellett KA, Cocklin SL, Hooper NM (2012) Alkaline phosphatase is increased in both brain and plasma in Alzheimer's disease. Neurodegener Dis 9: 31-37.

24. Johnson VJ, Tsunoda M, Sharma RP (2000) Increased production of proinflammatory cytokines by murine macrophages following oral exposure to sodium selenite but not to seleno-L-methionine. Arch Environ Contam Toxicol 39: $243-250$.

25. Sun K, Wu S, Wang Y, Wan X, Thompson HJ, et al. (2013) High-dose sodium selenite toxicity cannot be prevented by the co-administration of pharmacological levels of epigallocatechin-3-gallate which in turn aggravates the toxicity. Food Chem Toxicol 52: 36-41.
26. Sayato Y, HasegawaT, Taniguchi S, MaedaH, OzakiK, et al. (1993) Acute and subacuteoral toxicity of selenocystine in mice. Japanese Journal of Toxicology and Environmental Health 39: 289-296.

27. Zhang J, Wang H, Peng D, Taylor EW (2008) Further insight into the impact of sodium selenite on selenoenzymes: high-dose selenite enhances hepatic thioredoxin reductase 1 activity as a consequence of liver injury. Toxicol Lett 176: 223-229.

28. Jones DP (2006) Redefining oxidative stress. Antioxid Redox Signal 8: 1865 1879

29. Hasegawa T, Taniguchi S, Mihara M, Nakamuro K, Sayato Y (1994) Toxicity and chemical form of selenium in the liver of mice orally administered selenocystine for 90 days. Arch Toxicol 68: 91-95.

30. Schweizer U, Bräuer AU, Köhrle J, Nitsch R, Savaskan NE (2004) Selenium and brain function: a poorly recognized liaison. Brain Res Brain Res Rev 45 164-178.
This article was originally published in a special issue, Biomarkers: Toxicology handled by Editor(s). Dr. James V. Rogers, Wright State University, USA; Dr. Jagjit S. Yadav, University of Cincinnati, USA; Dr. Huixiao Hong, National Center for Toxicological Research, USA 